\title{
COMPOSICIÓN Y FUNCIONES DE LA FLORA BACTERIANA INTESTINAL
}

\author{
Mario Gómez Duque MD FCCM*, Fanny Acero MD**
}

\section{Resumen}

Las enfermedades gastrointestinales son una causa importante de morbilidad y mortalidad alrededor del mundo. Involucran enfermedades inflamatorias crónicas como colitis ulcerativa y enfermedad de Crohn, además de afecciones infecciosas y funcionales como el síndrome de intestino irritable. El tratamiento ha sido de difícil manejo dada la ambigüedad y las múltiples teorías que rodean la etiología. Se han relacionado elementos psicosociales, cambios en la motilidad gastrointestinal, factores inmunológicos, genéticos y hace poco alteraciones en la flora intestinal. Esta microflora bacteriana es un tema complejo y olvidado que contribuye de manera importante no sólo en los procesos de degradación y absorción de sustratos de la dieta, sino que cumple funciones inmunológicas y protectoras en cada organismo. Conocer su composición, distribución y las múltiples acciones que cumple para mantener el equilibrio en el ecosistema gastrointestinal, resulta esencial para comprender su participación en la prevención y tratamiento de trastornos inflamatorios y de la motilidad gastrointestinal.

Palabras clave: flora bacteriana, microflora intestinal, microbiota intestinal, flora fecal, microbiología intestinal, barrera inmunológica.

Abreviaturas: FBI, flora bacteriana intestinal; MFI, microflora intestinal.

\section{COMPOSITION AND FUNCTIONS OF INTESTINAL BACTERIAL FLORA}

\begin{abstract}
Gastrointestinal disorders are an important cause of morbidity and mortality worldwide. They involve chronic inflammatory bowel diseases such as ulcerative colitis and Crohn's disease, and infectious and functional disorders such as irritable bowel syndrome. Treatment has been difficult due to the ambiguity and multiple theories that are involved in their etiology. Psychological and social elements, changes in gastrointestinal motility, immunologic and genetic factors and recently, alterations of the intestinal flora, have been related. This bacterial microflora is a complex and forgotten topic with an important contribution not only to dietary substrate degradation and absorption processes but also fulfilling immunologic and protection functions in every organism. Knowing its composition, distribution and its multiple actions in maintaining proper balance of the gastrointestinal ecosystem is essential to understanding its role in preventing and treating inflammatory and gastrointestinal motility disorders.

Key words: bacterial flora, intestinal microflora, intestinal microbiota, fecal flora, intestinal microbiology, immunological barrier.

Fecha recibido: diciembre 2 de 2010 - Fecha aceptado: enero 27 de 2011

* Profesor Titular de Medicina Crítica, Fundación Universitaria de Ciencias de la Salud. Jefe de las Unidades de Cuidado Intensivo del Hospital de

San José, Hospital Infantil de San José y Clínica Fundadores. Bogotá D.C. Colombia.

** Residente II de Cirugía General, Fundación Universitaria de Ciencias de la Salud. Bogotá D.C. Colombia.
\end{abstract}




\section{Introducción}

El aumento en la incidencia de los trastornos de la función gastrointestinal sobre todo en poblaciones occidentales, ha dado pie a la hipótesis de su origen en la higiene, la cual postula queel aumento en la incidencia de rastornos mediados por el sistema inmune ocurre como consecuencia del aumento de mecanismos antiecológicos para prevenir las infecciones y la exposición a microorganismos durante la infancia. ${ }^{1}$ Las vacunas, el uso indiscriminado de antibióticos y el aumento de la alimentación con fórmulas en los recién nacidos, contribuyen a una alteración en la conformación normal de la flora intestinal y por ende, los pacientes quedan expuestos a la aparición de infecciones y trastornos gastrointestinales con mayor facilidad. ${ }^{2}$

Los estudios se han enfocado en evaluar las alteraciones en la composición de la MFI en pacientes con distintos trastornos gastrointestinales. Se ha reportado que el sobrecrecimiento bacteriano en el intestino delgado, por ejemplo, aumenta la fermentación y la producción de gas (dióxido de carbono, hidrógeno y metano), alterando así su motilidad. Estos factores son responsables de la alta prevalencia (80-90\%) de síntomas como la distensión abdominal, flatulencia, constipación o diarrea, presentes en muchas personas con diagnóstico de síndrome de intestino initable. ${ }^{3}$

\section{Flora bacteriana intestinal: generalidades}

La microflora intestinal se puede considerar como un órgano que se adquiere después del nacimiento. Está compuesta por una gran diversidad de bacterias que cumplen múltiples funciones. Tanto su composición como sus funciones están influenciadas por factores externos como el medio ambiente y la nutrición entre otros. ${ }^{4,5}$ Antonie van Leeuwenhoek (1632-1723) fue el primero en describir los microorganismos que habitan en el tracto gastrointestinal y los llamó animálculos. ${ }^{6}$ Pero fue Luis Pasteur en 1885 quien en la Academia Francesa de la Ciencia sugirió por primera vezquela microflora intestinal podía desempeñar un papel esencial en la digestión de los alimentos, creyendo que en su ausencia la digestión y metabolismo de éstos sería imposible?
Al principiolas descripciones sobre la composición eran sencillas, donde las bacterias descritas como predominantes en el ser humano eran el Clostridium perfringens, los Lactobacillus, Enterococcus, y Escherichia coli. ${ }^{8}$ En los años 60 Hugate desarrolló técnicas innovadoras de cultivos para bacterias habitantes del tracto gastrointestinal proximal en rumiantes y demostró la importancia de las anaeróbicas en los procesos de fermentación y del metabolismo de los alimentos. Después Holdeman y Moore modificaron las técnicas de Hungate para iniciar los estudios en seres humanos. $^{\text {? }}$

En la actualidad se sabe que la microflora intestinal involucra una gran diversidad de especies, de hecho se dice que existen más bacterias en la flora intestinal que células somáticas y germinales en el cuerpo, ${ }^{5}$ y que su número es diez veces mayor que el total de células en el cuerpo humano. ${ }^{9}$ Más del $99 \%$ de esta microflora está compuesta por bacterias que mantienen una relación de simbiosis con el ser humano ${ }^{10}$ y pueden dividirse en cuatro familias principales: Firmicutes, Bacteroidetes, Proteobacterias y Actinobacterias. ${ }^{11}$

La MFI ha sido asociada con efectos benéficos en el huésped, como la promoción de la maduración y la integridad del epitelio intestinal, protección contra patógenos y la modulación inmunológica. Además parece jugar un papel importante en el mantenimiento del equilibrio inmunológico intestinal y la prevención de la inflamación. ${ }^{4}$

Los anaerobios se encuentran en mayor proporción que los aerobios y la mayoría (60-90\%) son representantes de dos de las principales familias: los Bacteroides en un $23 \%$ y las Firmicutes $64 \% .^{12}$ Algunas especies de hongos también se han identificado como componentes de la microflora intestinal. ${ }^{13}$

A pesar de estar en contacto permanente con microorganismos en el medio ambiente, la composición de la MFI se mantiene estable. Sin embargo, se conoce muy poco acerca de los factores que pueden contribuir a preservar este equilibrio. Se hanimplicado tanto factores del huésped, como de las bacterias y otros adicionales 
como el uso de antibióticos en la creación y composición de la microbiota intestinal. ${ }^{4}$

Existen diferencias tanto en la concentración como en el tipo de microorganismos que la componen a lo largo de todo el tracto gastrointestinal. ${ }^{14}$ De hecho, la composición puede variar en forma transitoria como consecuencia de un importante inóculo bacteriano en la dieta o debido a condiciones patológicas tales como infecciones gastrointestinales, uso de antibióticos, antiácidos o estados de inmunosupresión. ${ }^{5}$

\section{Formación y cambios de la FBI con la edad}

Al nacer el intestino estéril del feto es colonizado por microorganismos del medio ambiente. ${ }^{4}$ Las Enterobacterias y las Bifidobacterias son las primeras y se dice que la composición está influenciada en este momento por el tipo de parto, niveles de higiene, medicamentos utilizados periparto y en el tipo de alimentación del recién nacido (Tabla 1) ${ }^{5,15}$ En estudios recientes se ha detectado que la microflora de los neonatos alimentados con leche materna está compuesta casi en forma exclusiva por Bifidobacterias, mientras que en aquellos que recibieron leche de fórmula se encontraron también Bacteroides, Enterobacterias y Streptococcus. ${ }^{4,5,15}$ Así mismo, se ha detectado un menor recuento de bacterias en cultivos realizados en las primeras semanas de vida en nacidos por cesárea que en aquellos por parto vaginal. ${ }^{16}$

En la medida que los niños empiezan a consumir alimentos más sólidos y sobre todo después del primero o segundo año de vida, la microflora cambia y comienza a formarse el esbozo de lo que va a ser la del adulto. ${ }^{16,17}$ Las Bifidobacterias constituyen sólo el 5-15\% del total, superadas por las Bacteroidetes, Eubacterias y Peptococcacea ${ }^{4}$ En la medida que pasan los años siendo más notorio en los ancianos, la motilidad intestinal disminuye retardando el tránsito y llevando a una alteración en el metabolismo de los nutrientes. Estos cambios afectan la composición de la MFI, produciendo una disminución de las especies de Bacteroides, Bifidobacterias y Lactobacillus, y un aumento de las Enterobacterias, Staphylococcus, Streptococcus y Candida a lbicans. ${ }^{16}$

\section{Composición de la FBI}

La superficie de la mucosa del tracto gastrointestinal humano es cerca de $300 \mathrm{~m}^{2}$ y está colonizada por cientos de especies bacterianas diferentes, con una concentración de $10^{13} \mathrm{a} 10^{14}$ en promedio. ${ }^{18}$ La estructura y composición de la FBI refleja la selección natural tanto a nivel microbiano como del huésped, la cual promueve la cooperación mutua para la estabilidad funcional de este ecosistema. ${ }^{19}$ Aunque predominan las bacterias (Tabla 2), también están presentes las Arqueas y Eucariotas. ${ }^{5} \mathrm{La}$ prevalencia de las bacterias en las diferentes partes del tracto gastrointestinal depende del $\mathrm{pH}$, el peristaltismo, las propiedades de adhesión bacteriana, la secreción de mucina que contiene inmunoglobulinas ( $\operatorname{Ig} \mathrm{A})$, la disponibilidad de nutrientes, la dieta y el antagonismo bacteriano, entre otras. ${ }^{20}$ La presencia de bacterias Gram negativas y positivas, aerobios y anaerobios como parte de la microflora, ha sido muy estudiada por métodos de cultivo y se ha demostrado diferencia en su número y

\begin{tabular}{|l|l|}
\hline \multicolumn{2}{|c|}{ Tabla I. Factores que intervienen en la composición de la flora* } \\
\hline Factor & \\
\hline Tipo de parto & Se retarda la colonización por Bacteroidetes, Bifidobacterias y E. coli en neonatos nacidos por cesárea. \\
Prematurez & Aumenta la colonización por Clostridium difficile. \\
Tipo de alimentación & Fórmulas ricas en oligosacáridos aumentan las colonias de Bifidobacterias. \\
Condiciones de higiene & Malas condiciones se relacionan con colonización temprana por Enterobacterias. \\
Unidad de recién nacidos & Exposición a antibióticos altera la composición normal de la microflora. \\
\hline
\end{tabular}

* Adaptado de Gastrointestinal microbiology. 2006. Taylor \& Francis Group. Arthur C. Caps: 2,3,4. 
composición en todas las diferentes porciones del tracto gastrointestinal. ${ }^{3,5}$

\begin{tabular}{|}
$\begin{array}{c}\text { Tabla 2. Microorganismos requeridos para la } \\
\text { estabilidad del ecosistema* }\end{array}$ \\
\hline \multicolumn{2}{|c|}{ Anaerobios } & Aerobios \\
\hline Bifidobacterium & Escherichia \\
Clostridium & Enterococcus \\
Bacteroides & Streptococcus \\
Eubacterium & Klebsiellas \\
\hline
\end{tabular}

* Adaptado de Gastrointestinal microbiology. 2006. Taylor \& Francis Group. Arthur C. Caps: 2,3,4.

De acuerdo con la actividad metabólica, las bacterias presentes en la MBI de los adultos pueden dividirse en tres grupos. ${ }^{18}$

1. Bacterias productoras de ácido láctico: incluyen Bifidobacterium, Lactobacillus, Streptococcus pneumoniae y Enterococcus.

2. Bacterias de putrefacción como Clostridium prefringens, Clostridium spp, Bacteroides, Peptococcaceae, Veillonella, E. coli, Staphylococcus y Pseudomona aeruginosa.

3. Otros tipos de microorganismos como Eubacterium, Ruminococcus, Megasphaera, Mitsuokello, C. butyricum y Candida.

El ácido clorhídrico y las secreciones biliares y pancreáticas impiden la colonización del estómago y el intestino delgado proximal por la mayoría de las bacterias, donde la concentración bacteriana varía entre $10^{1}$ y $10^{3}$ $\mathrm{cfu} / \mathrm{ml}$. La densidad bacterianaaumenta en la parte distal del intestino delgado con $10^{4} \mathrm{a} 10^{7} \mathrm{cfu} / \mathrm{ml}$ en yeyuno y en el intestino grueso se eleva a una cifra estimada entre $10^{11}$ y $10^{12} \mathrm{cfu} / \mathrm{ml}$ bacterias por gramo de colon. ${ }^{5} \mathrm{La}$ mayoría de las bacterias en el estómago no sobreviven por el $\mathrm{pH}$ bajo delmedio. Las concentraciones bacterianas detectadas son inferiores a $10^{3} \mathrm{cfu} / \mathrm{ml}$.

En pacientes sanos en ayuno y en momentos fisiológicos cuando la acidez gástrica se reduce como ocurre durante la noche y la fase I (quiescencia motora) del complejo motor migratorio. Los Enterococcus, Pseudomonas,
Streptococcus, Staphylococcus y Dentocariosas (Stomatococcus) se pueden aislar en cultivos de secreción gástrica $^{18,19}$ (Tabla 3).

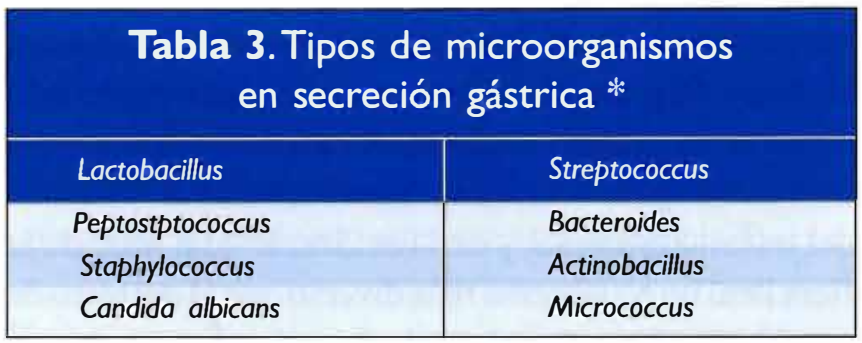

* Adaptado de Gastrointestinal microbiology. 2006. Taylor \& Francis Group. Arthur C. Caps: 2,3,4

El intestino delgado comprende el duodeno, yeyuno e îleon. La velocidad del contenido intraluminal del intestino delgado disminuye en la medida que se avanza desde el duodeno hasta el íleon. ${ }^{21}$ Los microorganismos aislados provienen de zonas proximales del tracto gastrointestinal como la boca, mediante la comida ingerida. Éstos descienden por el intestino unidos al quimo y durante el ayuno descienden por los movimientos del complejo motor migratorio. Éste último es a su vez lo que impide que microorganismos de áreas más distales del tracto colonicen el tracto gastrointestinal proximal en los períodos de ayuno. Portodolo anterior es que la densidad de la MFI aumenta hacia las áreas más distales. ${ }^{18}$

Los dos tercios superiores del intestino delgado, el duodeno y yeyuno, tienen una baja concentración de microorganismos, entre $10^{3}$ y $10^{5}$ bacterias $/ \mathrm{ml}$. Múltiples estudios han mostrado especies de Gram positivos como Lactobacillus y Streptococcus como predominantes en

Tabla 4. Distribución de microorganismos*

\begin{tabular}{|l|l|}
\hline Duodeno y yeyuno proximal & Yeyuno distal e íleon \\
\hline Lactobacillus & Bifidobacterias \\
Streptococcus & Clostridium \\
Veilonellas & Bacteroides \\
Staphylococcus & Fusobacterium \\
Actinobacillus & \\
Candida albicans & \\
Haemophillus & \\
Levaduras & \\
\hline
\end{tabular}

* Adaptado de Gastrointestinal microbiology. 2006. Taylor \& Francis Group. Arthur C. Caps: 2,3,4. 
su microflora, mientras que en zonas más distales los anaerobios y Gram negativos son los predominantes ${ }^{18}$ (Tabla 4). La microflora del íleon semeja en su gran mayoría a la del colon, debido al paso de microorganismos del ciego a través de la válvula ileocecal ${ }^{22}$ causando un aumento en la carga bacteriana con una concentración de $10^{7}$ a $10^{8} \mathrm{ctu} / \mathrm{ml}$. Además en esta zona terminal del intestino delgado ocurre una disminución en la velocidad del tránsito intestinal y de la acidez, lo cual hace de la flora ileal un ecosistema más diverso que el del resto de porciones del intestino delgado. ${ }^{23}$

El intestino grueso desde el ciego hasta el recto contiene más de 500 géneros de bacterias, ${ }^{3}$ con una concentración de $10^{11}$ a $10^{12}$ ufc/ml. ${ }^{24}$ La microflora del colon está compuesta en especial por anaerobios en un $99,9 \%$; sin embargo, Bacteroides, Bifidobacterias, Eubacteria, Clostridios y Enterobacterias también se han aislado ${ }^{22}$ (Tabla 5). A pesar de múltiples factores que pueden influenciar la composición y distribución de la flora bacteriana, bajocondiciones normales el ecosistema se mantiene en equilibrio, eliminando así posibles patógenos que alteren su composición normal. ${ }^{4}$

Tabla 5. Microorganismos en el intestino grueso*

Clostridium levaduras

Propionibacterium actinobacterium

Enterobacterias eubacterium

Bacteroides fusobacterium

Veillonella staphylococcus

* Adaptado de Gastrointestinal microbiology. 2006. Taylor \& Francis Group. Arthur C. Caps: 2,3,4.

\section{Funciones de la MFI}

Lasfunciones de la MFI se pueden dividir en grandes grupos: metabólicas, protectoras e inmunológicas.

\section{- Funciones metabólicas}

El tracto gastrointestinal es uno de los órganos desde el punto de vista inmunológico más activos del cuerpo humano. La gran mayoría de sus funciones están moduladas por la acción de la $\mathrm{FBI}^{22}$, entre las cuales la principal es la de ahorro de energía mediante la fermentación de carbohidratos como la fibra de los vegetales y los oligosacáridos. ${ }^{25}$

La microflora es también capaz de sintetizar algunas vitaminas como B y K. ${ }^{18}$ Además, gracias al proceso de fermentación ${ }^{22}$ produce ácidos grasos de cadena corta: acetato, butirato y propionato, en orden de frecuencia. ${ }^{18}$ Ellos funcionan como fuente energética para las células: el acetato para los miocitos, el butirato para los enterocitos y el propionato para los hepatocitos. ${ }^{18}$

Los microorganismos más eficientes para la producción de ácidos grasos de cadena corta son las Firmicutas en especial las especies Clostridium y Bifidobacterium. ${ }^{13}$ En esta forma influyen en el metabolismo, controlan la proliferación de células epiteliales y su diferenciación, la función de las microvellosidades, tienen impacto sobre la motilidad intestinal y su función de absorción de agua, y la regulación hepática de lípidos y azúcares. ${ }^{21}$

\section{- Funciones protectoras e inmunológicas}

El efecto protector de la MFI ante agentes patógenos se divide en dos: resistencia a la colonización y estimulación del sistema inmune. En pacientes sanos, la microflora residente evita la colonización y/o sobrecrecimiento de patógenos, lo cual sigue siendo motivo de estudio. ${ }^{22} \mathrm{Se}$ han descrito múltiples mecanismos que protegen al huésped de infecciones oportunistas, como la competencia por sitios de adhesión, la de nutrientes y la producción de condiciones ambientales hostiles para el crecimiento de patógenos que involucran cambios en el $\mathrm{pH}^{2}$, la producción de compuestos antimicrobianos (desde metabolitos tóxicos hasta sustancias bactericidas) y la generación de señales que intervienen en la expresión de génica. ${ }^{18}$

La respuesta protectora del epitelio intestinal se puede dividir en una barrera secretora, diseñada para evitar qué bacterias patógenas entren en contacto con la superficie de los enterocitos y una barrera física por medio de una capa de moco epitelial ${ }^{26}$, la cual está construida por glicoproteínas mucinosas que contribuyen a la formación de unapelícula gelatinosa sobre la superficie epitelial del 
intestino. Sin embargo, no sólo ejerce esta actividad protectora, sino que causa secreción de IgA y de péptidos y proteínas antimicrobianas transportadas a través de la lámina propia porlas células epiteliales hacia la monocapa de mucina. ${ }^{27}$

A pesar del rápido recambio epitelial que ocurre cada tres a cinco días ${ }^{28}$, las células epiteliales del intestino son capaces de funcionar como una barrera importante contra productos microbianos como los lipopolisacáridos y las endotoxinas presentes en el intestino. Al mismo tiempo, permiten el paso de nutrientes, electrolitos y agua de la luz intestinal hacia el torrente sanguíneo. Esta permeabilidad selectiva a través de la capa de enterocitos está dada por uniones estrechas en el extremo apical y lateral de las membranas celulares, las cuales son estructuras dinámicas cuya función puede ser regulada por estímulos externos. ${ }^{27}$

La MFI estimula la función inmune tanto a nivel local como sistémico. Las interacciones entre la mucosa, la microflora gastrointestinal y el tejido linfoide asociado con el intestino (GALT) son fundamentales para la defensa del huésped contra la invasión patógena y la infección. ${ }^{18,22}$ Las bacterias comensales influyen en el desarrollo de los componentes humorales del sistema inmune de la mucosa y también modulan la producción de las citoquinas por parte de las células $T$ y $T$-helper (Th) tipo 1 ó tipo 2, influenciando las funciones de las células dendríticas, de linfocitos B y de las epiteliales. ${ }^{5,29}$ Aunque los mecanismos exactos de estas interacciones son desconocidos, al parecer forman parte fundamental del equilibrio del ecosistema del tracto gastrointestinal y es aquí donde se define el límite entre la convivencia y el inicio de una respuesta inmune. ${ }^{1}$

En personas sanas las bacterias comensales inducen cierto grado de tolerancia inmunológica, en contraste con la reacción inflamatoria agresiva que se produce frente a patógenos ajenos a la flora normal. La habilidad del intestino para diferenciar la flora normal de microorganismos patógenos involucra procesos de vigilancia y reconocimiento inmunológico. Se considera que algunos de estos procesos complejos y no bien entendidos hasta el momento, están presentes desde el nacimiento y otros se van adquiriendo durante la vida con la exposición a los microorganismos. ${ }^{21}$

\section{Cambios de la FBI en enfermos críticos}

Se dice que la mucosa intestinal tiene más terminaciones nerviosas que cualquier otro tejido en el organismo. Cuando se está bajo estrés se produce liberación de noradrenalina en la luz intestinal, lo cual reduce el número de bacterias comensales y hace que los microorganismos con potencial patógeno aumenten su virulencia. ${ }^{30}$

Estudios realizados en animales han demostrado una disminución importante en la flora bacteriana normal después de cuatro a seis horas de iniciado el proceso patológico de una enfermedad. Además, hay evidencia de sobrecrecimiento bacteriano e inicio de traslocación bacteriana tan temprano como las seis primeras horas. En pacientes críticos se ha reportado una pérdida total de la FBI después de una estancia corta en unidades de cuidados intensivos. ${ }^{30}$ Esto es importante ya que es una de las teorías que podrían hacernos entender la razón de la traslocación bacteriana, sepsis e inicio de falla orgánica multisistémica en muchos de estos casos.

\section{La FBI como factor desencadenante en diferentes patologías}

\section{- Enfermedad inflamatoria intestinal}

La enfermedad de Crohn y la colitis ulcerativa son afecciones inflamatorias crónicas cuya etiología no es clara aún. Dentro de las múltiples teorías sobre su etiología se ha considerado la FBI como un factor esencial en el inicio y propagación del proceso inflamatorio que las caracteriza. ${ }^{31}$ Se considera que en pacientes genéticamente susceptibles, la interacción entre una respuesta anormal del sistema inmune asociado con mucosas y los microorganismos que componen la FBI, puede ser uno de los mecanismos que influyen en su fisiopatología. ${ }^{32}$

Además de la interacción con el GALT se han encontrado muchas otras posibles formas en las que la FBI y sus alteraciones determinan la aparición de trastornos inflamatorios intestinales. Dentro de éstas, también se han descrito la hiperreactividad de los linfocitos $T$ en 
pacientes con enfermedad de Crohn contra microorganismos de la flora intestinal normal y el aumento en niveles de IgG en la colitis ulcerativa que reaccionan contra la microflora. ${ }^{31}$

Otros estudios han encontrado diferencias en la composición de la MFI de los pacientes con enfermedad inflamatoria intestinal comparándolos con personas sanas y aquellos con colitis ulcerativa y enfermedad de Crohn, lo que hace suponer que influye en la aparición de este tipo de trastornos. ${ }^{11}$ Se cree que no es sólo el predominio de algunos de géneros bacterianos sobre otros lo que hace importante estas diferencias cuando se trata de entender la fisiopatología sino que su alteración modifica este ecosistema tan complejo produciendo la afección.

Es aquí donde se revela la importancia de las funciones de la FBI normal para la prevención. Se ha demostrado que el butirato, ácido graso de cadena corta producido por la microflora y que es el metabolito principal para el aporte de energía a los enterocitos en el $70 \%$, tiene la capacidad de disminuir la expresión de citoquinas proinflamatorias como el factor de necrosis tumoralá y â (TNF-á, TNF-â), interleuquina-6(IL-6) e interleuquina IL-1, en pacientes con enfermedad inflamatoria intestinal. ${ }^{13}$

\section{- Sindrome de intestino irritable}

Su fisiopatología multifactorial es indeterminada, donde al parecer hay cambios en el número y composición de la MFI. En 1980 Balsari demostró una disminución en el número de Coliformes, Lactobacillus y Bifidobacterias en las heces de pacientes con síndrome de intestino irritable. Sin embargo, desde entonces no ha habido nuevos estudios que lo sustenten. ${ }^{11}$

\section{- Cáncer de colon}

La flora intestinal juega un papel importante en el desarrollo del cáncer de colon mediante la producción de carcinógenos y procarcinógenos. ${ }^{11}$ Se ha descrito que la dieta rica en grasas y carnes, pero con bajo contenido de fibra vegetal, aumenta la excreción de compuestos nitrosos en las heces, conocidos como sustancias promotoras del cáncer de colon. También se ha visto que las aminas aromáticas heterocíclicas que son producto de carnes cocinadas, inducen a cierto tipo de bacterias de la FBI para alterar la metilación del DNA de los enterocitos, afectando el adecuado uso del butirato por las células que impide la síntesis normal de la película de moco epitelial intestinal. ${ }^{25,31}$ Los Bacteroides y Clostridium aumentan la incidencia de aparición y frecuencia de crecimiento de tumores en el colon según se ha visto en estudios en animales, mientras que géneros como Lactobacillus y Bifidobacterias parecen tener efectos protectores. ${ }^{31}$ Aunque la evidencia que soporta esta información todavía no es conclusiva, se considera la FBI como un factor importante que influye en el riesgo de aparición y desarrollo del cáncer de colon en seres humanos. ${ }^{31}$

\section{- Obesidad}

Se ha descrito en estudios en roedores y en humanos que la obesidad se relaciona con alteraciones en la composición de la FBI. Se ha reportado una disminución del $50 \%$ en la población de Bacteroides y un aumento proporcional en los Firmicutes en relación con la flora bacteriana de personas sanas no obesas. ${ }^{33}$ Esto sustenta la teoría de que la diferencia entre poblaciones de microorganismos que componen la FBIlleva a diferencias en el metabolismo de los sustratos y también a la producción y uso de la energía. ${ }^{25}$ Por lo tanto, se ha relacionado la alteración en la composición de la microflora como factor que puede contribuir en la fisiopatología de enfermedades metabólicas. ${ }^{34}$

\section{Probióticos y prebióticos}

Con los hallazgos sobre alteraciones en la flora gastrointestinal como posible causa contribuyente del desarrollode múltiples patologías gastrointestinales, desde inflamatorias como funcionales hasta neoplásicas, se ha empezado a considerar el uso de bacterias de la microflora como medidas de prevención y de manejo de algunas de estas patologías. ${ }^{35-37}$

Es así como aparecen los probióticos, descritos por primera vez por Fuller en $1989^{38-40}$ y que no son más que microorganismos vivos que al seringeridos en cantidades suficientes ejercen beneficios sobre el huésped. Los Lactobacillus, Bifidobacterias y Saccharomyces sobre 
todo los L. casei, L. rhamnosus, L. acidophillus, $L$. plantarum, B. longum, B. bifidum y $S$. cerevisiae boulardii, son los más utilizados. ${ }^{1,15,41}$ Los prebióticos son sustancias no digeribles, que al ser consumidas en cantidades suficientes estimulan la reproducción y actividad de cierto tipo de microorganismos de la flora, dándole de igual forma beneficios al huésped. ${ }^{17,30,42}$ Ejemplos de éstos son oligosacáridos, fructooligosacáridos e inulina los cuales estimulan el metabolismo y la producción de Bifidobacterium. ${ }^{38.43,44}$ Aunque no es el tema de esta revisión, vale la pena nombrarlos, ya que sonmotivo de múltiples estudios en la actualidad y pueden ser el futuro en la prevención y tratamiento de patologías gastrointestinales de alta prevalencia y con un porcentaje importante de morbimortalidad en la población.

\section{Conclusión}

La FBI juega un papel destacado en la fisiopatología gastrointestinal. Se puede considerar como un órgano compuesto por más de 500 géneros de bacterias, las cuales contienen treinta veces más genes que el resto del cuerpo humano, ${ }^{30,45,46}$ que es esencial para el desarrollo del sistema inmune gastrointestinal asociado con mucosas, para el mantenimiento de un entorno fisiológico protegiendo al huésped de infecciones oportunistas, por sus efectos tróficos sobre el epitelio intestinal y para actividades metabólicas que se traducen en recuperación de energía y procesamiento de sustratos de la dieta.

La FBI es también un factor importante en la fisiopatología de múltiples trastornos patológicos, incluyendo el síndrome de intestino irritable, el cáncer de colon y las enfermedades inflamatorias del intestino. Su pérdida es un factor a tener en cuenta en pacientes críticos en unidades de cuidados intensivos, donde aumenta el riesgo de infecciones oportunistas y así mismo de traslocación bacteriana. Basados en estos hallazgos, aunque aun son materia de estudio, se han empezado a utilizar como método de prevención o tratamiento de algunas de estas enfermedades en forma de probióticos y prebióticos..$^{31,47-49}$

El uso indiscriminado de antibióticos asociado con un inadecuado manejo intrahospitalario de los nutrientes y las condiciones predisponentes de los enfermos como la hipoperfusión tisular o la desnutrición, causan cambios en la ecología intestinal produciendo graves consecuencias como la sepsis persistente por translocación bacteriana, multirresistencia, disfunción orgánica y muerte. La nutrición enteral temprana asociada o no con el uso de pro y prebióticos son factores que contribuyen de manera importante a mantener la motilidad y conservar la flora disminuyendo la mortalidad y las complicaciones. ${ }^{50-53}$

\section{Referencias}

1. Denise K. Importance of microbial colonization of the gut in early life to the development of immunity. Mutat Res. 2007; 622 (1-2), 58--69.

2. Imke E, et al. Environmentally-acquired bacteria influence microbial diversity and natural innate immune responses at gut surfaces. BMC Biol. 2009; 7:79.

3. Ringel Y, Carroll IM. Alterations in the intestinal microbiota and functional bowel symptoms. Gastrointest. Endosc Clin N Am. 2009 Jan; 19(1):141-50.

4. Schiffrin EJ, Blum S. Interactions between the microbiota and the intestinal mucosa. Eur J Clin Nutr. 2002 Aug;56 Suppl 3:S60-4.

5. O'Hara AM, Shanahan F.. The gut flora as a forgotten organ. EMBO Rep. $2006 \mathrm{Jul} ; 7(7): 688-93$.

6. Zoetendal EG, Cheng B, Koike S, Mackie RI. Molecular microbial ecology of the gastrointestinal tract : from phylogeny to function. Curr Issues Intest Microbiol. 2004 Sep;5(2):31-47.

7. Tannock GW. New perceptions of the gut microbiota : implications for future research. Gastroenterol Clin North Am. 2005 Sep;34(3):361-82, vii.

8. Tannock GW. Variation in human intestinal microbiota with age. Gastroenterol Clin North Am. 2005 Sep;34(3):361-82, vii

9. Xu J, Mahowald MA, Ley RE, Lozupone CA. Evolution of symbiotic bacteria in the distal human intestine. PLoS Biol. 2007 Jul;5(7):el56

10. Pai R, Kang G. Microbes in the gut: A digestable account of host-symbiont interactions. Indian J Med Res. 2008 Nov;128(5):587-94

11. Ojetti V, Gigante $\mathrm{G}$, et al. Microflora imbalance and gastrointestinal diseases. Dig Liver Dis suppl. 2009 Jul; 3(2): 35-9.

12. Hattori M, Taylor TD. The human intestinal microbiome : a new frontier of human biology. DNA Res. 2009 Feb;16(1):1-12

13. Neish AS. Microbes in gastrointestinal health and disease. Gastroenterology. 2009 Jan; $136(1): 65-80$.

14. Mazuski JE, Solomkin JS. Intra-abdominal infections. Surg Clin North Am. 2009 Apr; 89(2):421-37

15. Weng M, Walker W. Bacterial colonization, probiotics, and clinical disease. J Pediatr: 2006 nov; 149(5): S 107-S114.

16. O'Toole PW, Claesson MJ. Gut microbiota : changes throughout the lifespan from infancy to elderly. Int Dairy J. 2010 Apr; 20(4): 281-91. 
17. Tiihonen $\mathrm{K}$, Ouwehand AC, Rautonen N. Human intestinal microbiota and healthy ageing. Ageing Res Rev. 2010 Apr;9(2):107-16.

18. Ouwehand AC, Vaughan EE, editors. Gastrointestinal microbiology. New York : Informa Healthcare; 2006.

19. Mazzone A, Farrugia G. Evolving concepts in the cellular control of gastrointestinal motility: neurogastroenterology and enteric sciences. Gastroenterol Clin North Am. 2007 Sep; 36(3):499-513.

20. Farrell RJ, LaMont JT. Microbial factors in inflammatory bowel disease. Gastroenterol Clin North Am. 2002 Mar; 31(1):41-62.

21. Savage DC. Mucosal microbiota. In: Mestecky J, Lamm ME, Strober W, editors. Mucosal immunology. $3^{\text {rd }}$ ed. Burlington, MA : Elsevier; 2005, p. 19-33.

22. Cebra JJ, Jiang HQ, Boiko N, Tlaskalova-Hogenova $\mathrm{H}$. The role of mucosal microbiota in the development, maintenance, and pathologies of the mucosal immune system. In: Mestecky J, Lamm ME, Strober W, editors. Mucosal immunology. $3^{\text {rd }}$ ed. Burlington, MA : Elsevier; 2005. p. 335-368.

23. Aziz RK. A hundred-year-old insight into the gut microbiome. Gut Pathog. $2009 \operatorname{Dec} 7 ; 1(1): 21$.

24. Zoetendal EG, von Wright A, Vilpponen-Salmela T. Mucosa-associated bacteria in the human gastrointestinal tract are uniformly distributed along the colon and differ from the community recovered from feces. Appl Environ Microbiol. 2002 Jul; 68(7):3401-7.

25. Montalto M, D'Onofrio F, et al. Intestinal microbiota and its functions. Dig Liver Dis suppl. 2009 Jul; 3(2): 30-4

26. Neish AS. The gut microflora and intestinal epithelial cells: a continuing dialogue. Microbes Infect. 2002 Mar; 4(3):309-17.

27. Mahida YR. Microbial-gut interactions in health and disease. Epithelial cell responses. Best Pract Res Clin Gastroenterol. 2004 Apr; 18(2):241-53.

28. Kalliomäki MA, Walker WA. Physiologic and pathologic interactions of bacteria with gastrointestinal epithelium. Gastroenterol Clin North Am. 2005 Sep;34(3):383-99.

29. Thompson-Chagoyán OC, Maldonado J, Gil A. Aetiology of inflammatory bowel disease (ibd): role of intestinal microbiota and gut-associated lymphoid tissue immune response. Clin Nutr. 2005 Jun; 24(3):339-52.

30. Bengmark S. Bioecologic control of the gastrointestinal tract: the role of flora and supplemented probiotics and synbiotics. Gastroenterol Clin North Am. 2005 Sep;34(3):413-36

31. Guamer F, Malagelada JR. Gut flora in health and disease. Lancet. $2003 \mathrm{Feb}$ 8;361(9356):512-9

32. Royero HA. Enfermedad inflamatoria intestinal. Rev Colomb Gastroenterol $2003 ; 18$ (1) :24-41.

33. Marchesi J, Shanahan F. The normal intestinal microbiota. Curr Opin Infect Dis. 2007 Oct;20(5):508-13

34. Cani PD, Delzenne NM. The role of the gut microbiota in energy metabolism and metabolic disease. Curr Pharm Des. 2009;15(13):1546-58.
35. Bengmark S. Ecological control of the gastrointestinal tract. The role of probiotic flora. Gut. $1998 \mathrm{Jan} ; 42(1): 2-7$.

36. Madden JA, Hunter JO. review of the role of the gut microflora in irritable bowel syndrome and the effects of probiotics. Br J Nutr. 2002 Sep; 88 Suppl 1:S67-72

37. Culligan EP, Hill C, Sleator RD. Probiotics and gastrointestinal disease: successes, problems and future prospects. Gut Pathog. 2009 Nov 23;1(1): 19

38. Park J, FlochMH. Prebiotics, probiotics, and dietary fiber in gastrointestinal disease. Gastroenterol Clin North Am. 2007 Mar; 36(1):47-63.

39. Almeida J, Galhenage S, Yu J, Kurtovic J, Riordan SM. Gut flora and bacterial translocation in chronic liver disease. World J Gastroenterol. 2006 Mar 14;12(10):1493-502

40. Quigley EM. Bacteria: a new player in gastrointestinal motility disordersinfections, bacterial overgrowth, and probiotics. Gastroenterol Clin North Am. 2007 Sep;36(3):735-48

41. Doron S, Snydman DR, Gorbach SL. Lactobacillus GG: bacteriology and clinical applications. Gastroenterol Clin North Am. 2005 Sep;34(3):483-98

42. AndohA, Fujiyama Y. Therapeuticapproachestargeting intestinal microflora in infl ammatory bowel disease. World J Gastroenterol 2006 July 28; 12(28): 4452-60.

43. Rioux KP, Madsen KL, Fedorak RN. The role of enteric microflora in inflammatory bowel disease: human and animal studies with probiotics and prebiotics. Gastroenterol Clin North Am. 2005 Sep;34(3):465-82.

44. Walker WA. introduction. Am J Clin Nutr. 2001 Jun;73(6):1121S-1123S

45. Wilks M. Bacteria and early human development. Early Hum Dev. 2007 Mar; 83(3): 165-70

46. Iapichino G, Callegari ML, Marzorati S. Impact of antibiotics on the gut microbiota of critically ill patients. J Med Microbiol. $2008 \mathrm{Aug}$; 57(Pt 8): $1007-14$

47. Serino $M$, Luche E, Chabo C, Amar J, Burcelin R. Intestinal microflora and metabolic diseases. Diabetes Metab. 2009 Sep; 35(4):262-72.

48. Vaahtovuo J, Korkeamäki M, Munukka M, et al. Microbial balance index a view on the intestinal microbiota. Livest Sci. 2007 May; 109 (1-3), 17478 .

49. SchwiertzA, Jacobi M, Frick JS, Richter M, Rusch K, Köhler H. Microbiota in pediatric inflammatory bowel disease. J Pediatr. 2010 Aug;157(2):240 244

50. Gómez M, Posada C, Cruz LE. Soporte nutricional en cuidado intensivo experiencia de 4 años. Acta Col Cuidado Intensivo. 2001; 4(2): 109.

51. Fioramonti J, Theodorou V, Bueno L. Probiotics: what are they? What are their effects on gut physiology?. Best Pract Res Clin Gastroenterol. 2003 Oct; $17(5): 711-24$

52. Berg RD. The indigenous gastrointestinal microflora. Trends Microbiol. 1996 Nov;4(11):430-5.

53. Mshvildadze M, Neu J. The infant intestinal microbiome: friend or foe? Early Hum Dev. 2010 Jul;86 Suppl 1:67-71. 